\title{
PEMBUATAN SISTEM INFORMASI COMPANY PROFILE BERBASIS WEBSITE SMPN 4 GUNUNGSARI
}

\author{
(The Making of Website based Information System of Company Profile for SMPN 4 \\ Gunungsari)
}

\author{
Yuniar Islamiati ${ }^{[1]}$, Andy Hidayat Jatmika ${ }^{[1]}$, Farid Wahyudi ${ }^{[2]}$ \\ ${ }^{[1]}$ Dept Informatics Engineering, Mataram University \\ J1. Majapahit 62, Mataram, Lombok NTB, INDONESIA \\ ${ }^{[2]}$ Sekolah Menengah Pertama Negeri 4 Gunungsari \\ Jl. Jagapati, Lombok Barat, Lombok NTB, INDONESIA \\ Email: y.islmiati@gmail.com, andy@unram.ac.id,wdie9998@gmail.com
}

\begin{abstract}
Abstrak
Perkembangan teknologi informasi sangat mendukung dalam perkembangan berbagai sektor, salah satunya bidang pendidikan. Teknologi informasi pada bidang Pendidikan sebagai media pengetahuan dan promosi. SMPN 4 Gunungsari merupakan sekolah menengah pertama negeri yang melayani pengajaran dan pendidikan menengah di Kabupaten Lombok Barat. SMPN 4 Gunungsari memiliki banyak kelebihan sebagai penunjang dan poros pendidikan. Namun perlu adanya platform guna mempromosikan sekolah tersebut agar dapat memperlihatkan kelebihan sekolah di masyarakat luas. Selain itu, informasi mengenai pendidikan menjadi kebutuhan umum bagi masyarakat saat ini, banyak orang tua yang bingung dalam menentukan sekolah yang baik untuk putra-putrinya, dikarenakan minimnya informasi mengenai sekolah. Oleh karena itu dengan berkembangnya kemajuan teknologi ini, dibuatlah Sistem Informasi Company Profile Berbasis Website dengan menggunakan bahasa pemrograman PHP, database MySQL dan framework Codeigniter 3 agar masyarakat dapat dengan mudah mengakses dan mengetahui segala sesuatu mengenai SMPN 4 Gunungsari dengan jelas dan tanpa memerlukan banyak waktu. Metode yang digunakan adalah waterfall dengan beberapa tahapan yang runtut dari analisis kebutuhan, desain sistem, coding dan testing, penerapan program, serta pemeliharaan. Pengujian menggunakan user acceptance testing yang di dalamnya terdapat pengujian black box dan kuesioner. Berdasarkan pengujian yang telah dilakukan, maka didapatkan hasil bahwa responden yang merupakan seluruh tenaga pendidik dan staf di SMPN 4 Gunungsari setuju dengan sistem informasi profile company yang telah dibuat.
\end{abstract}

Keywords: Teknologi Informasi, Sistem Informasi, Website, Metode Waterfall, User Acceptance Testing

\section{Pendahuluan}

\subsection{Latar Belakang}

Di era globalisasi ini perkembangan ilmu pengetahuan dan teknologi menjadi sangat cepat, khususnya dibidang teknologi informasi. Perkembangan teknologi informasi sangat mendukung dalam perkembangan berbagai sektor, seperti perdagangan, pendidikan, komunikasi, perindustrian, pariwisata, dan lain sebagainya. Sehingga pada bidang pendidikan salah satu fungsi teknologi informasi sebagai media pengetahuan, dan promosi [1].

SMPN 4 Gunungsari merupakan sekolah menengah pertama negeri yang melayani pengajaran dan pendidikan menengah di Kabupaten Lombok Barat. Sekolah Menengah Pertama (SMP) menjadi jenjang pendidikan formal tingkat menengah yang memiliki tujuan meningkatkan kecerdasan, pengetahuan, kepribadian, akhlak mulia, serta keterampilan untuk hidup mandiri dan menyiapkan siswa menuju ke jenjang pendidikan lebih lanjut [2]. SMPN 4 Gunungsari memiliki banyak kelebihan sebagai penunjang dan poros pendidikan. Namun, perlu adanya platform guna mempromosikan sekolah tersebut agar dapat memperlihatkan kelebihan sekolah di masyarakat luas. Selain itu, informasi mengenai pendidikan menjadi kebutuhan umum bagi masyarakat saat ini, banyak orang tua siswa yang bingung dalam menentukan sekolah yang baik untuk putra-putrinya, dikarenakan minimnya informasi mengenai sekolah. Sehingga membuat masyarakat dan calon siswa mencari informasi seputar sekolah dengan cara mendatangi sekolah yang menyebabkan penyampaian informasi menjadi tidak efektif dan efisien.

Oleh karena itu, dengan berkembangnya kemajuan teknologi ini, SMPN 4 Gunungsari perlu mempromosikan dan memberikan informasi tentang profil sekolah, lokasi, serta keunggulan yang dimiliki sekolah melalui sebuah website online di internet. Dengan sebuah website, masyarakat dapat dengan mudah mengakses dan mengetahui segala sesuatu mengenai SMPN 4 Gunungsari dengan jelas dan tanpa memerlukan banyak waktu. Informasi mengenai sekolah ini nantinya dapat diakses oleh semua orang melalui internet tanpa batasan ruang dan waktu. Sehingga sistem informasi company profile digunakan karena tidak dapat menyebabkan data-data hilang sewaktuwaktu. Maka dari itu, pada pengabdian masyarakat ini perlu dibuat sebuah "Sistem Informasi Company Profile 
Berbasis Website SMPN 4 Gunungsari” yang diharapkan mampu mengatasi kesalahan-kesalahan yang terjadi juga dapat memudahkan dalam proses mempromosikan sekaligus mengenalkan sekolah kepada masyarakat luas.

\subsection{Rumusan Masalah}

Berdasarkan latar belakang, maka dapat dirumuskan pokok permasalahan yaitu bagaimana cara merancang dan membuat sistem informasi company profile berbasis website pada SMPN 4 Gunungsari?

\subsection{Batasan Masalah}

Batasan masalah pada praktek kerja lapangan ini adalah sebagai berikut:

1. Sistem hanya menampilkan informasi sekolah, tenaga pengajar, kontak yang dapat dihubungi serta informasi-informasi terkini seperti berita, agenda dan pengumuman terbaru sekolah.

2. Sistem yang dibangun merupakan sebuah sistem informasi yang dapat dikelola oleh operator SMPN 4 Gunungsari.

3. Sistem dibuat berbasis web dengan menggunakan Bahasa pemrograman PHP dan MySQL serta framework Codeigniter 3 .

\subsection{Tujuan}

Tujuan dari pengabdian masyarakat yang dilakukan yaitu merancang dan membuat sistem informasi company profile berbasis website SMPN 4 Gunungsari.

\subsection{Manfaat}

Manfaat pembuatan sistem informasi company profile berbasis website adalah sebagai berikut:

1. Untuk SMPN 4 Gunungsari.

a. Meningkatkan eksistensi sekolah.

b. Menarik lebih banyak masyarakat umum untuk mendaftarkan pendidikan di SMPN 4 Gunungsari.

c. Dapat mengetahui informasi seklah dimana saja dan kapan saja dengan mudah.

2. Untuk Mahasiswa

a. Menerapka ilmu yang telah di pelajari selama masa perkuliahan.

b. Mampu menghadapi sekaligus mengatasi masalah yang muncul ketika di dunia kerja.

\section{Tinjauan Pustaka}

\subsection{Company Profile}

Company profile yaitu gambaran umum mengenai diri suatu perusahaan yang hendak melakukan serangkaian promosi terpadu melalui sebuah buku atau media lain[3]. Company profile menginformasikan tentang nilai-nilai positif suatu perusahaan, lembaga atau instansi baik pemerintah maupun swasta, agar mendapatkan suatu tanggapan yang positif(simpati dari masyarakat), sehingga keberadaan perusahaan bisa di terima oleh masyarakat[4].

\subsection{Sistem Informasi}

Sistem digunakan untuk menjelaskan beberapa komponen-komponen yang berkaitan antara satu sama lain yang bekerja bersama-sama guna mencapai tujuan umum, yaitu menerima masukan-masukan serta menghasilkan keluaran-keluaran pada suatu proses transformasi yang terorganisir[5]. Sedangkan sistem informasi merupakan suatu sistem yang bertujuan untuk pengolahan kebutuhan transaksi harian guna mendukung fungsi operasi organisasi yang bersifat manajerial dengan kegiatan strategi dari suatu organisasi untuk menyediakan kebutuhan kepada pihak luar dengan informasi yang akan diperlukan dalam pengambilan keputusan[6]. Pada sistem yang telah dibuat dapat dilakukan berbagai aktivitas seperti menyimpan, mengambil, mengubah, mengolah dan mengkomunikasikan informasi yang akan diterima oleh sistem informasi atau peralatan sistem lainnya[7].

\subsection{Basis Data}

Basis data terdiri dari 2 kata, yaitu basis dan data. Basis kurang lebih diartikan sebagai markas atau gudang, tempat bersarang/berkumpul. Sedangkan data adalah representasi fakta dunia nyata yang mewakili suatu objek seperti manusia, barang, hewan, peristiwa, konsep, keadaan, dan sebagainya, yang direkam dalam bentuk angka, huruf, simbol, teks, gambar, bunyi/suara, atau kombinasinya [8]. 


\subsection{Aplikasi Berbasis Web dan Website}

World Wide Web atau yang biasa disebut web, merupakan salah satu sumber daya internet yang berkembang pesat. Teknologi web memanfaatkan bahasa yang disebut HTML (Hyper Text Markup Language) dan protokol yang digunakan dinamakan HTTP (Hyper Text Tansfer Protocol). Perkembangan berikutnya, sejumlah skrip dan objek dikembangkan, seperti PHP, ASP, dan applet (Java) [9]. Sedangkan website merupakan sebuah kumpulan halaman-halaman web beserta file-file pendukungnya, seperti file gambar, video, dan file digital lainnya yang disimpan pada sebuah web server yang umumnya dapat diakses melalui internet[10].

\section{$2.5 \quad \mathrm{UML}$}

Unified Modelling Language merupakan alat perancangan sistem yang berorientasi pada objek. UML diagram memiliki tujuan utama untuk membantu tim pengembangan proyek berkomunikasi, mengeksplorasi potensi desain, dan memvalidasi desain arsitektur perangkat lunak atau pembuat program [11]. UML adalah bahasa yang menggambarkan cara kerja maupun struktur menggunakan konsep OOP (Object Oriented Programming), sehingga dapat dilihat dari struktur data yang diberikan [12].

\subsection{ERD}

ERD (Entity Relationship Diagram) merupakan sebuah diagram yang digunakan untuk merancang hubungan antar tabel-tabel dalam basis data [8]. ERD (Entity Relation Diagram) berguna untuk menggambarkan gambaran dari dunia nyata yang akan diterapkan pada suatu database sebuah sistem. Dengan ERD sendiri dapat membantu mengurangi kesalahan - kesalahan dalam melakukan perancangan database dari gambaran dunia nyata dan struktur database seperti redudansi data, hubungan - hubungan antara entitas, dan lain sebagainya.

\subsection{PHP}

PHP digunakan sebagai bahasa script server-side dalam pengembangan web yang disisipkan pada dokumen HTML. Penggunaan PHP memungkinkan web dapat dibuat dinamis sehingga maintenance situs web tersebut menjadi lebih mudah dan efisien [13].

\section{$2.8 \quad M y S Q L$}

MySQL merupakan DBMS open source (kode programnya dapat di-download gratis) dan freeware (gratis dipakai), walau gratis MySQL tidak bisa dikatakan DBMS kurang baik karena gratis, hal ini terbukti dengan adanya sebuah operator telepon selular yang menggunakan DBMS ini dan memiliki sistem yang andal dengan optomasi. Sampai saat ini MySQL masih menjadi DBMS open source paling banyak digunakan di dunia. MySQL terkenal dengan kecepatan dalam pengaksesan datanya. MySQL saat ini dimiliki oleh perusahaan Oracle [14].

\subsection{Bootstrap}

Bootstrap merupakan framework untuk membangun desain web secara responsif. Artinya, tampilan web yang dibuat oleh bootstrap akan menyesuaikan ukuran layer dan browser yang kita gunakan baik di desktop, tablet ataupun mobile device. Dengan bootstrap kita juga bisa membangun web dinamis ataupun statis [15].

\subsection{XАMPP}

XAMPP adalah perangkat lunak bebas yang mendukung banyak sistem informasi, merupakan kompilasi dari beberapa program. Fungsinya adalah sebagai server yang berdiri sendiri (localhost), yang terdiri atas program Apache, HTTP Server, MySQL database, dan penerjemah bahasa yang ditulis dengan bahasa pemrograman PHP dan Perl [16].

\section{Metode Pengabdian masyarakat}

\subsection{Metode Perancangan Sistem}

Pada pengabdian masyarakat ini metode yang digunakan adalah metode waterfall. Metode waterfall menjadi metode yang merancang sistem secara berurutan dimulai dari perancangan hingga maintenance seperti yang tergambar pada Gambar 1. Metode waterfall menjadi salah satu jenis model pengembangan aplikasi dengan pendekatan yang sistematis, Dalam pengembangannya metode waterfall memiliki beberapa tahapan yang runtut yaitu analisis kebutuhan, desain sistem, penulisan kode program, pengujian program dan penerapan program dan pemeliharaan. Proses pembuatan sistem informasi company profile sekolah SMPN 4 Gunungsari dimulai dengan melakukan identifikasi masalah yang ada pada sekolah tersebut melalui wawancara dan observasi ke lokasi. Dari hasil wawancara dan observasi ke lokasi diputuskan informasi-informasi yang akan ditampilkan di dalam sistem 
yang akan dibuat. Kemudian dilanjutkan dengan analisis kebutuhan yang diperlukan dalam pembuatan sistem. Selanjutnya dilakukan perancangan sistem jika telah selesai dilakukan dilakukan pembuatan sistem. Setelah program selesai dibuat, kemudian dilakukan implementasi dan testing dari sistem yang dibuat. Jika program berhasil, maka akan dilanjutkan dengan sosialisasi dan penyerahan sistem kepada pihak SMPN 4 Gunungsari, namun sebaliknya jika program belum berhasil, maka akan dilakukan perbaikan dimulai dari perancangan sistem, dan akan terus diulang sampai program berhasil dan selesai.

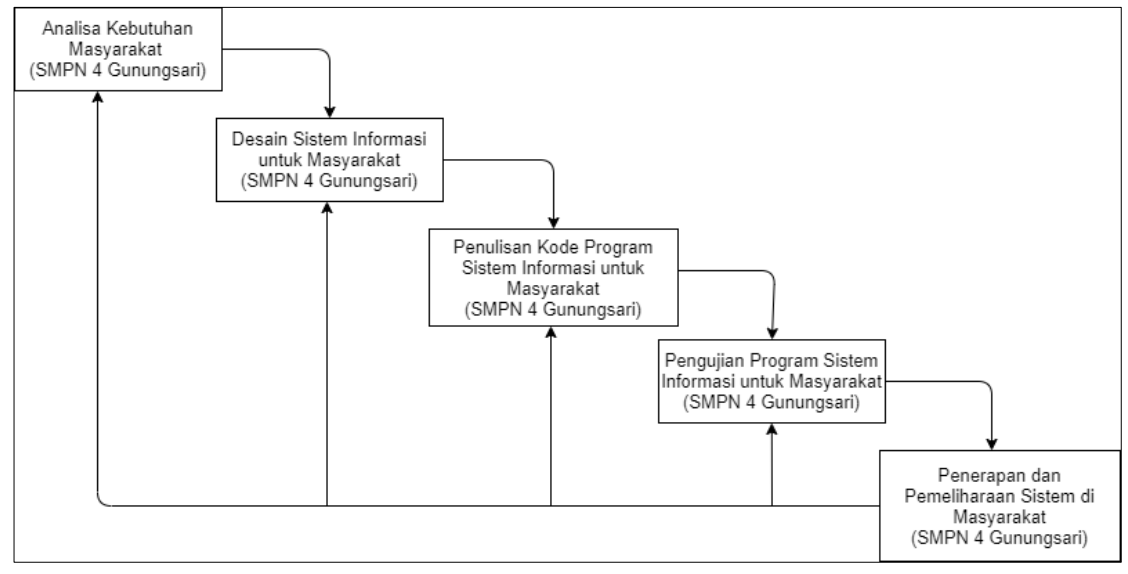

Gambar 1. Metode pengabdian masyarakat waterfall

\subsection{Desain Sistem}

Pada sistem informasi company profile berbasis website SMPN 4 Gunungsari memiliki diagram sebagai berikut:

\subsubsection{Use Case Diagram}

Gambar 2 merupakan usecase diagram pada sistem informasi company profile berbasis website. User dari sistem ini adalah:

1. Pengunjung

Dalam sistem informasi ini, pengunjung dapat melihat data melihat informasi sekolah, tenaga pengajar, kontak yang dapat dihubungi serta informasi-informasi terkini seperti berita, agenda dan pengumuman terbaru sekolah.

2. Administrator

Dalam sistem informasi ini, administrator dapat melakukan beberapa hal berikut ini:

a. Melihat semua data, yaitu data dashboard, list berita/artikel, kategori berita/artikel, data administrator, data file berkas, data album galeri, data photo galeri, data guru, pesan yang ditinggalkan dan komentar pada artikel.

b. Edit atau update beberapa data, yaitu data list berita/artikel, kategori berita/artikel, data administrator, data file berkas, data album galeri, data photo galeri, dan data guru.

c. Hapus atau delete beberapa data, yaitu data list berita/artikel, kategori berita/artikel, data administrator, data file berkas, data album galeri, data photo galeri, data guru, pesan yang ditinggalkan dan komentar pada artikel.

d. Tambah beberapa data, yaitu data list berita/artikel, kategori berita/artikel, data administrator, data file berkas, data album galeri, data photo galeri, dan data guru.

e. Mencari beberapa data, yaitu data data list berita/artikel, kategori berita/artikel, data administrator, data file berkas, data album galeri, data photo galeri, data guru, pesan yang ditinggalkan dan komentar pada artikel.

f. Melakukan reset password apabila administrator lain lupa password.

g. Mapat membalas komentar pada artikel/berita.

h. Melakukan login sebelum melihat data.

i. Melakukan logout setelah login. 


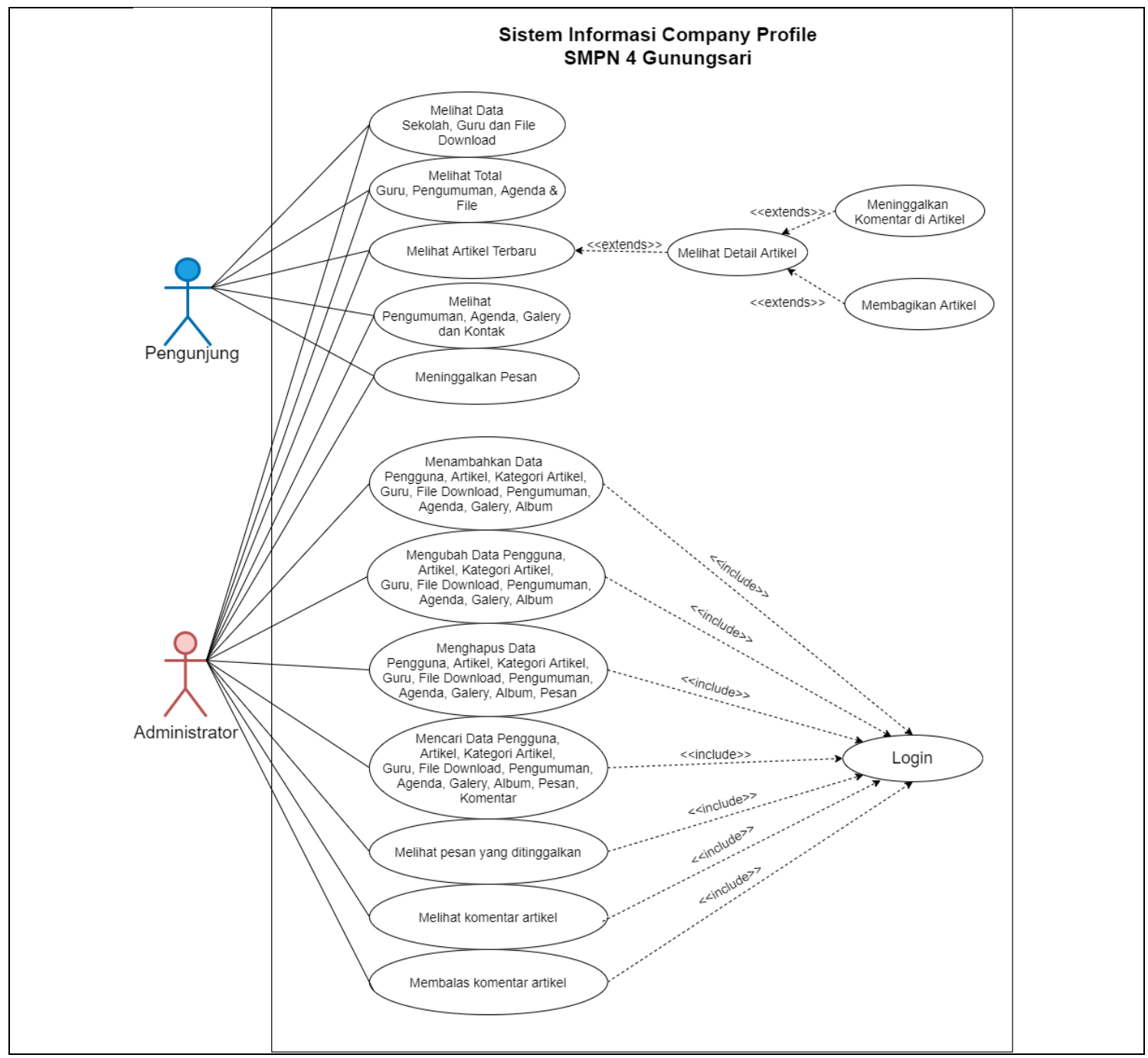

Gambar 2. Use case diagram sistem informasi company profile SMPN 4 Gunungsari

\subsubsection{Sequence Diagram}

Berikut merupakan sequence diagram dari sistem informasi company profile SMPN 4 Gunungsari:

a. Login

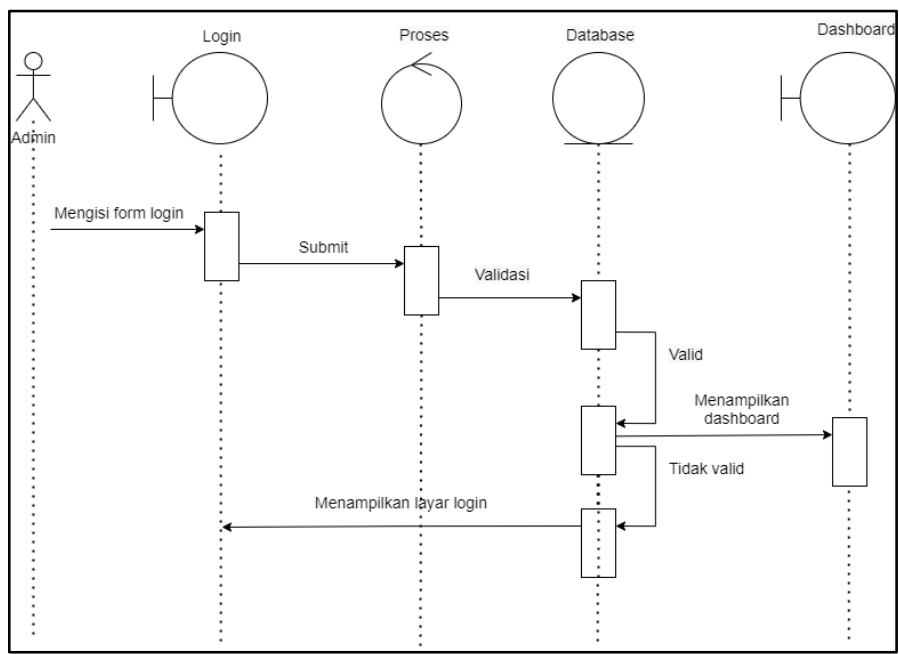

Gambar 3. Sequence diagram login 
Gambar 3 merupakan sequence diagram dari melakukan login. Berdasarkan sequence diagram tersebut, saat melakukan login sistem akan menampilkan form login yang kemudian akan diisi oleh admin sesuai dengan akun yang dimiliki setelah admin akan melakukan submit dan selanjutnya sistem akan melakukan proses cek validasi dari data yang dimasukan admin tadi, apabila data sesuai dengan database maka sistem akan berpindah ke halaman dashboard jika tidak maka akan tetap pada halaman login.

b. Tambah data berita

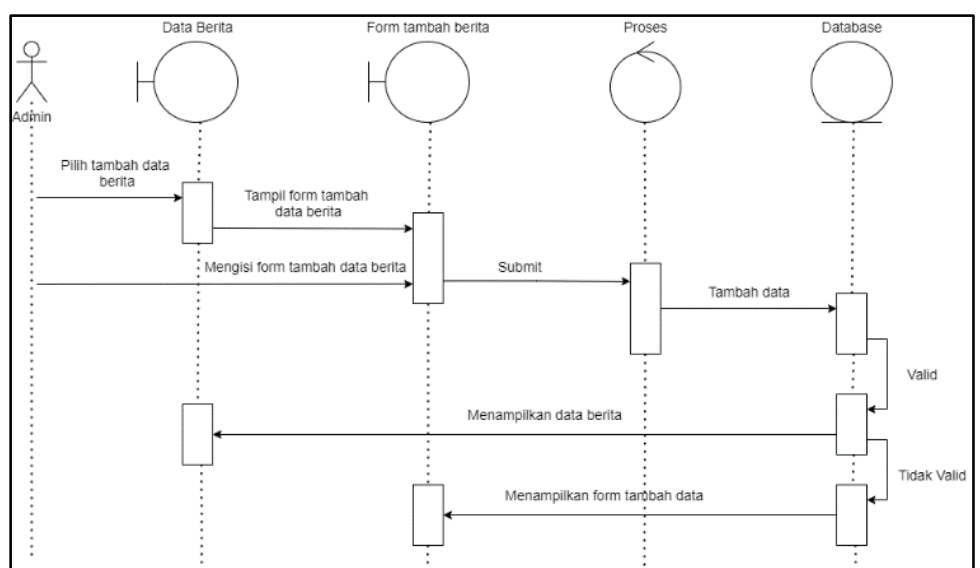

Gambar 4. Sequence diagram tambah data berita

Pada Gambar 4 merupakan sequence diagram dari melakukan proses tambah data berita. Tambah data berita dilakukan dengan memilih menu tambah data pada halaman data berita. Setelah itu sistem akan menampilkan form untuk menambah data berita. Setelah di submit dan diproses. Data yang sudah diproses jika valid akan tersimpan pada database dan admin dibawa ke halaman data berita. Jika data tidak valid maka admin akan dibawa ke halaman form tambah data.

\subsubsection{Activity Diagram}

Berikut merupakan activity diagram dari sistem informasi company profile SMPN 4 Gunungsari:

a. Login

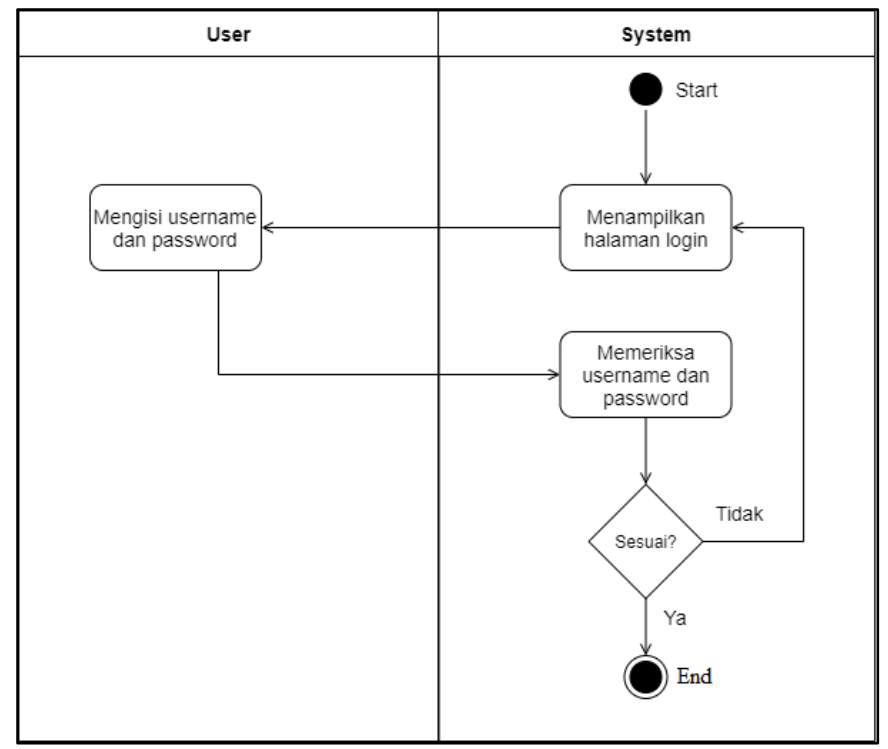

Gambar 5. Activity diagram login

Gambar 5 merupakan activity diagram dari proses login. Proses login sistem akan menampilkan form log in yang akan diisi oleh admin, apabila data sesuai maka sistem akan berpindah ke halaman dashboard jika tidak maka akan tetap pada halaman login. 
b. Tambah data

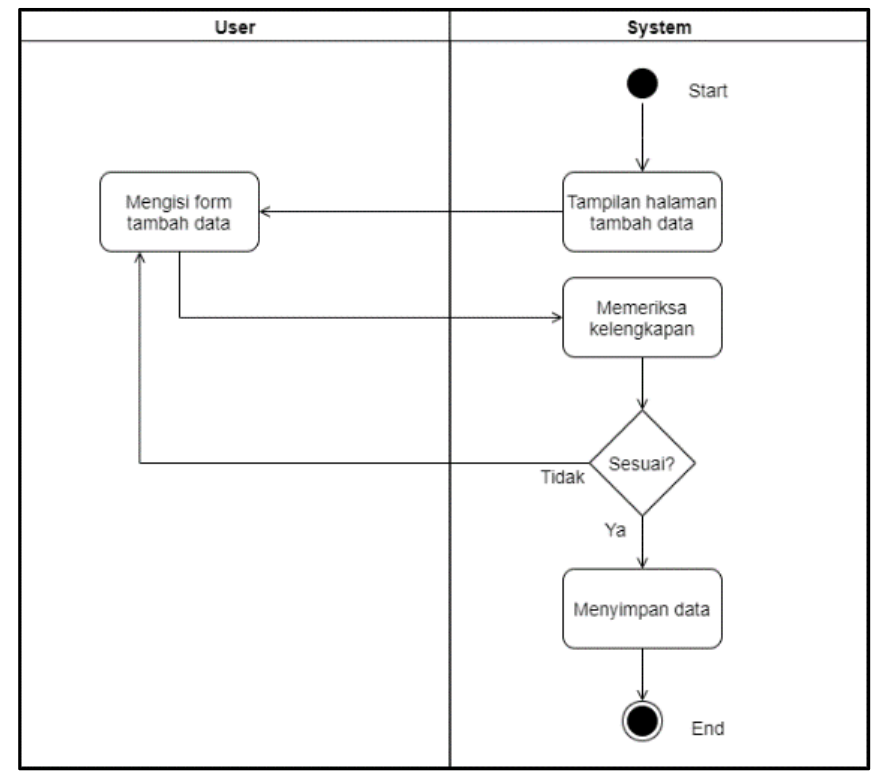

Gambar 6. Activity diagram tambah data

Pada gambar 6 merupakan activity diagram dari proses tambah data. Sistem akan menampilkan halaman untuk menambahkan data, setelah itu admin akan mengisi data sesuai dengan yang dibutuhkan, lalu sistem akan memeriksa data yang telah diisi. Jika data telah diisi dengan lengkap maka data akan disimpan ke dalam database, jika tidak maka perlu dilengkapi kembali data yang belum terisi.

\subsubsection{EntityRelationship Diagram (ERD)}

Berikut pada gambar 8 adalah ERD (Entity Relationship Diagram) dari sistem informasi informasi company profile SMPN 4 Gunungsari:

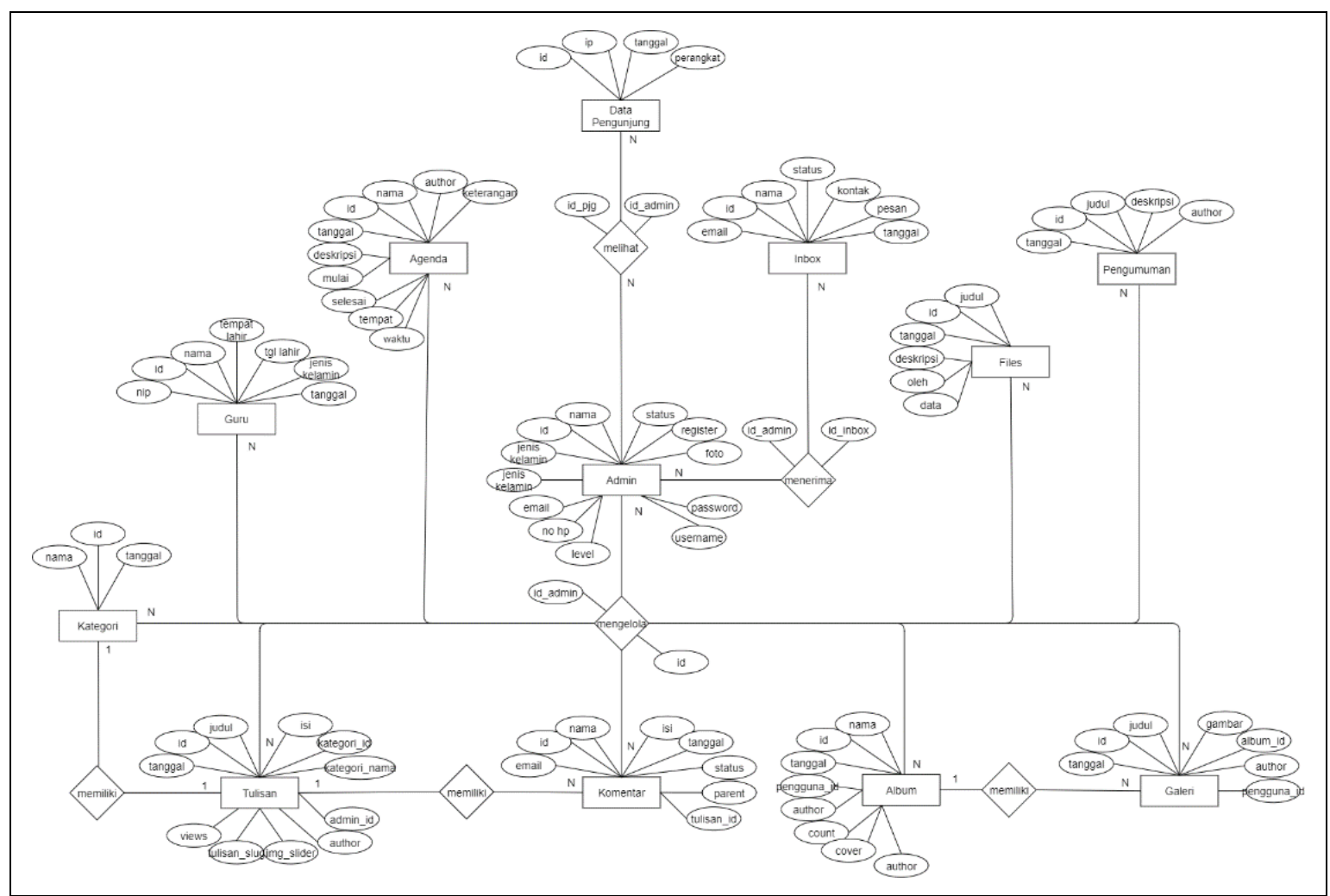

Gambar 7. ERD sistem informasi company profile 


\subsection{Implementasi Sistem}

\subsubsection{Implementasi Interface Sistem}

Berikut adalah implementasi tampilan (interface) program dari sistem evaluasi komunikasi dan stakeholder

a. Homepage

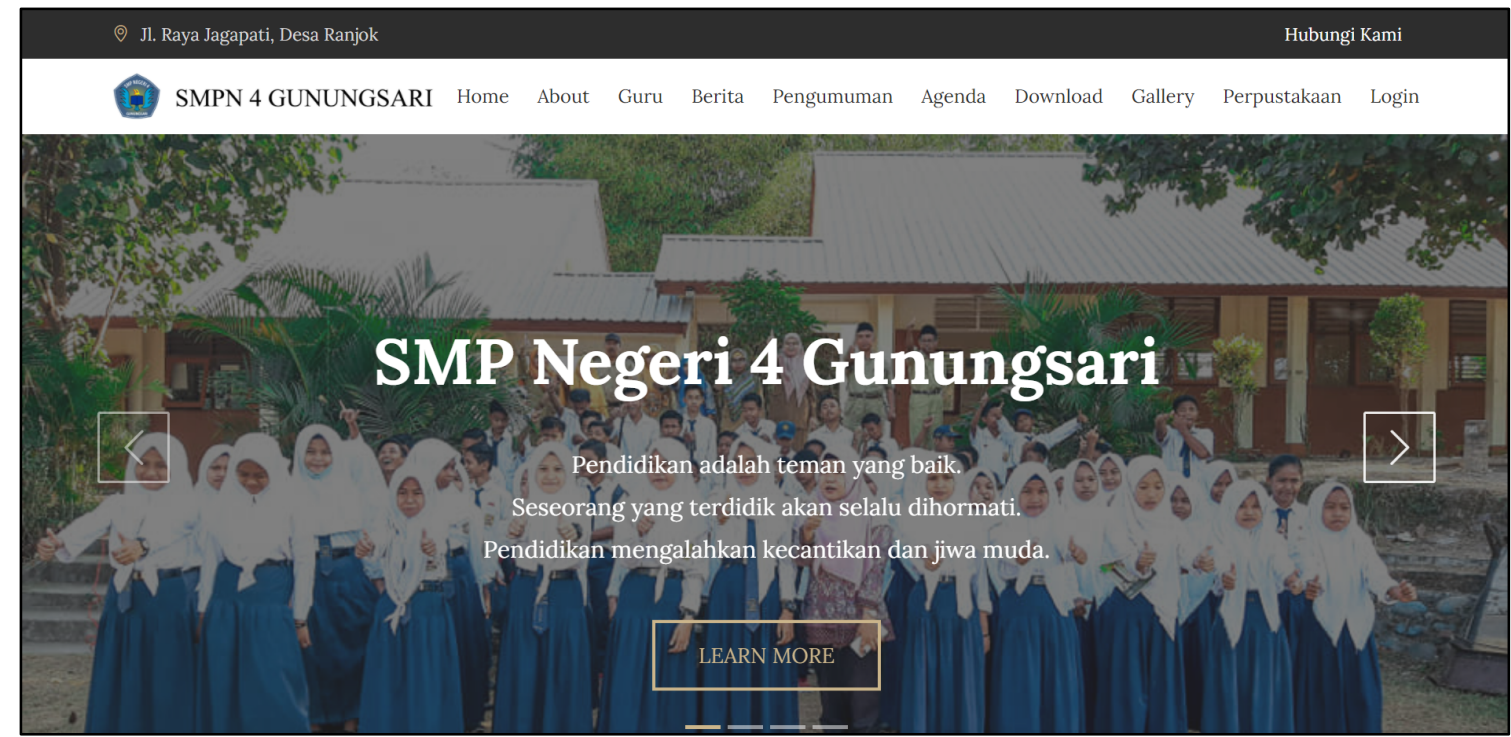

Gambar 8. Homepage

Pada gambar 8 merupakan implementasi halaman home user dalam sistem informasi company profile pada SMPN 4 Gunungsari. Halaman ini adalah halaman yang akan ditampilkan saat user mengunjungi domain "https://smpn4gunungsari.sch.id/". Pada halaman home berisikan informasi-informasi mengenai ringkasan isi dari website yang ada.

b. Halaman Guru

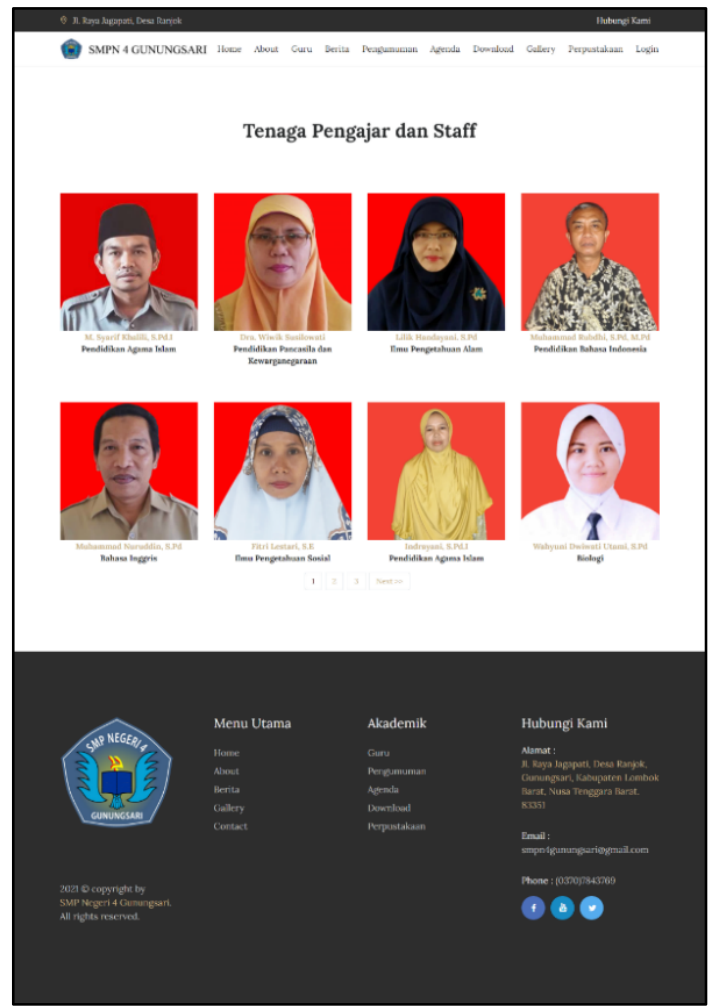

Gambar 9. Halaman guru 
Pada gambar 9 merupakan implementasi dari halaman data guru dan staff SMPN 4 Gunungsari. Pada halaman ini berisikan daftar nama-nama guru yang mengajar beserta mata pelajaran yang diajarkan. Terdapat fitur next untuk melihat nama-nama guru selanjutnya.

c. Halaman kontak

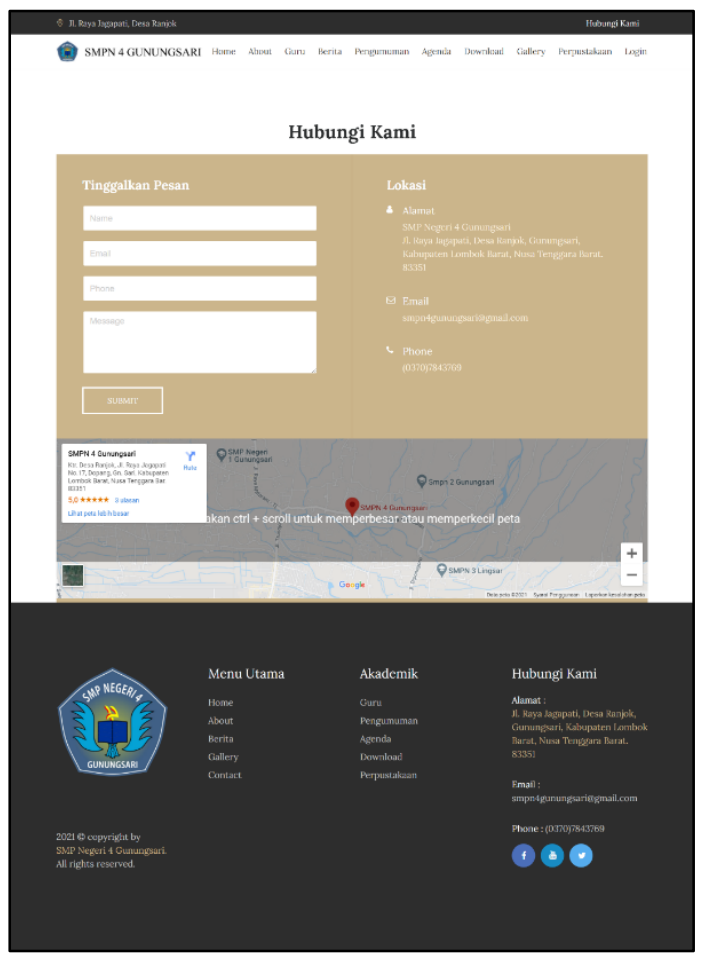

Gambar 10. Halaman kontak

Pada gambar 10 merupakan implementasi dari kontak yang dapat dihubungi pengujung website. Kontak yang tersedia berupa halaman google maps atau denah sekolah yang dapat dikunjungi, email, phone serta media sosial dari SMPN 4 Gunungsari.

d. Login

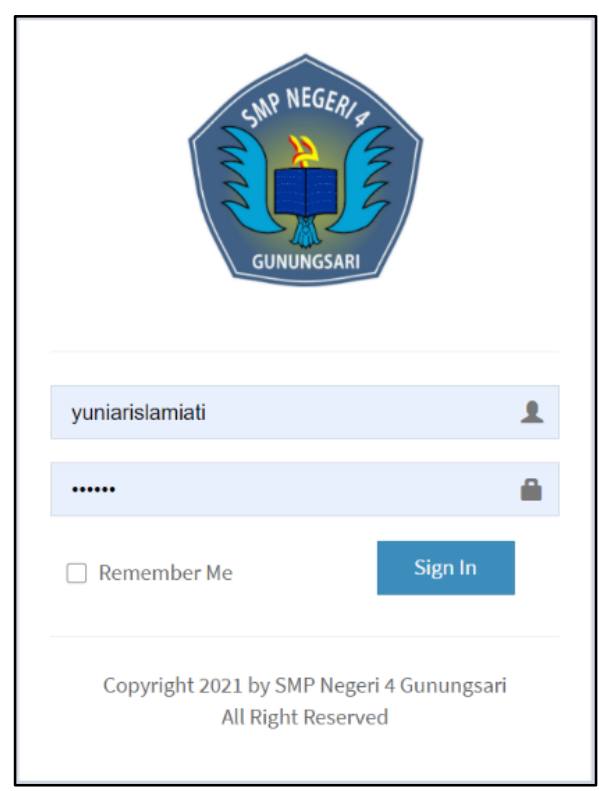

Gambar 11. Halaman login

Pada gambar 11 merupakan implementasi dari halaman login administrator dalam sistem informasi company profile pada SMPN 4 Gunungsari. Halaman ini adalah halaman yang pertama kali ditampilkan saat admin akan login ke sistem informasi. 


\section{e. Dashboard}

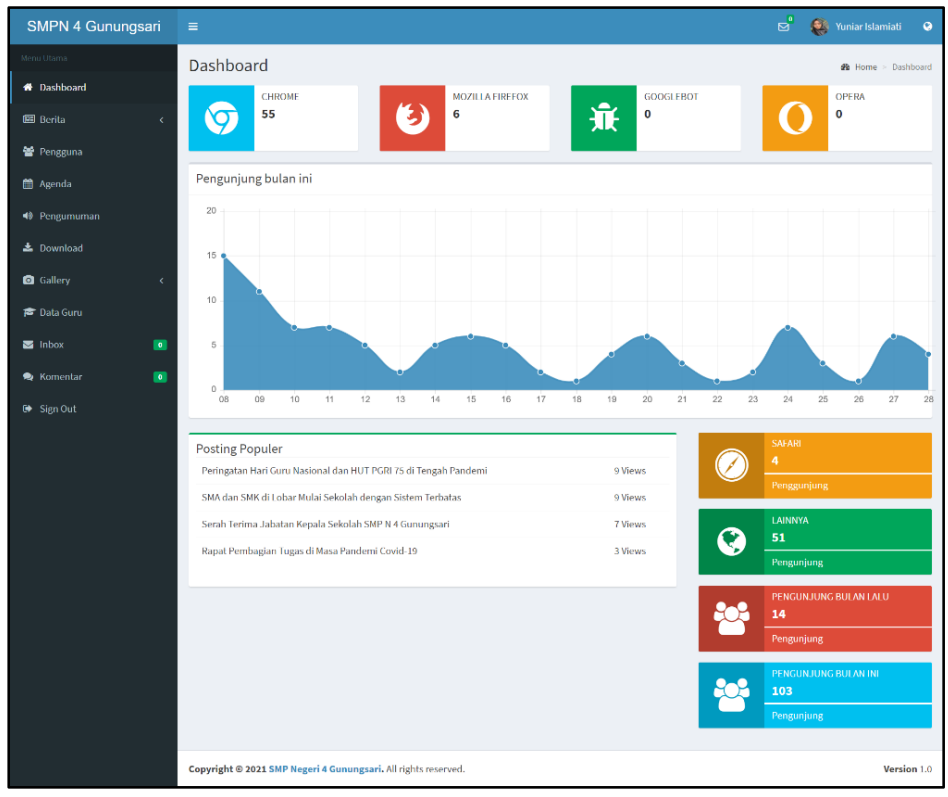

Gambar 12. Halaman dashboard admin

Pada gambar 12 merupakan implementasi dari halaman dashboard dalam sistem informasi company profile pada SMPN 4 Gunungsari. Halaman ini adalah halaman yang akan menampilkan jumlah total pengunjung saat admin akan login ke sistem informasi.

f. Halaman data pengguna

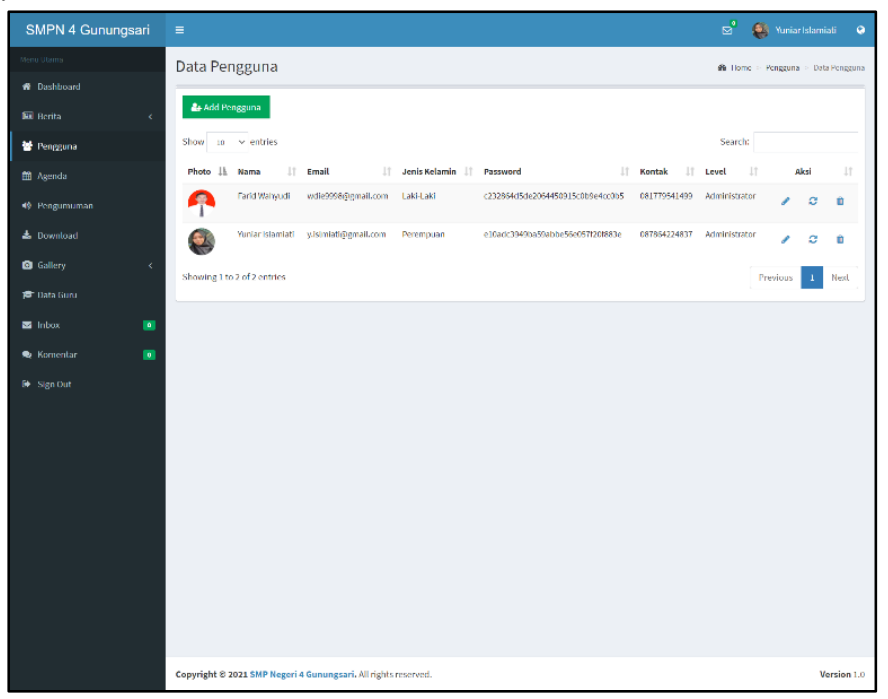

Gambar 13. Halaman data pengguna

Pada gambar 13 merupakan implementasi dari halaman data pengguna dalam sistem informasi company profile pada SMPN 4 Gunungsari. Halaman ini adalah halaman yang menyimpan data-data administrator sekolah.

\section{HaSil DaN PEMbahasan}

Testing sistem informasi company profile pada SMPN 4 Gunungsari menggunakan metode user acceptance testing. Metode user acceptance testing menggunakan black box testing dan kuesioner dalam pengujiannya. Berikut hasil dari testing yang telah dilakukan:

\subsection{Black Box Testing}

Metode pengujian black box merupakan metode pengujian yang menguji fungsi-fungsi di dalam sistem untuk menentukan apakah fungsi-fungsi tersebut sudah berjalan sesuai harapan atau tidak. Berdasarkan pengujian black 
box yang telah dilakukan pada seluruh fitur yang terdapat dalam sistem, fitur-fitur tersebut diuji dengan berbagai data masukan. Sehingga didapat kesimpulan bahwa fitur-fitur yang ada pada sistem informasi company profile pada SMPN 4 Gunungsari telah berjalan dengan baik.

\subsection{Kuisioner}

Pengujian dengan menggunakan kuesioner dilakukan dengan cara mencari responden yang merupakan operator dan guru untuk melakukan uji coba sistem dan menjawab pernyataan pada kuesioner yang diberikan. Parameter pengujian yang digunakan pada metode ini adalah :

a. Apakah sistem yang dibuat sudah sesuai dengan kebutuhan SMPN 4 Gunungsari?

b. Apakah sistem yang dibuat mempermudah untuk mengenalkan SMPN 4 Gunungsari kepada masyarakat?

c. Apakah sistem yang dibuat mudah digunakan?

d. Apakah sistem memberikan informasi yang detail?

e. Dalam tata letak (desain), apakah sistem mudah untuk dipahami?

Responden akan diberikan pilihan jawaban dari pertanyaan-pertanyaan di atas, yaitu :

a. Iya

b. Tidak
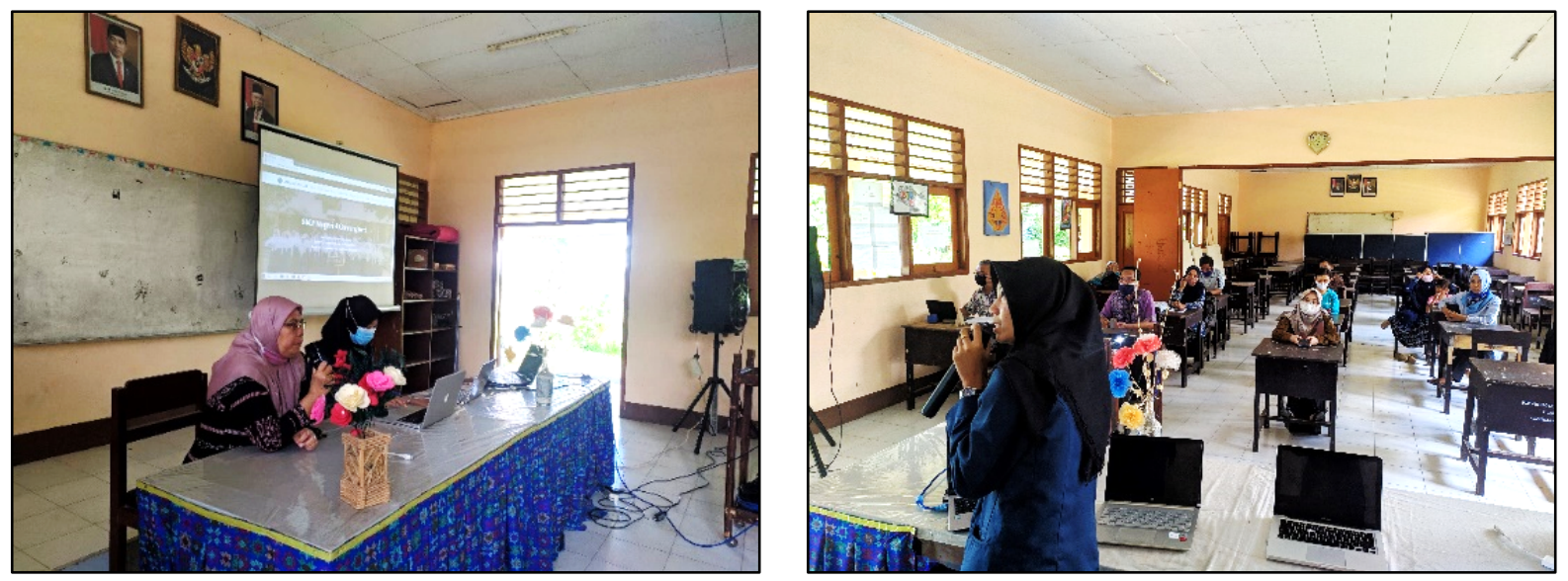

Gambar 14. Presentasi pengujian sistem

Hasil rekapitulasi jawaban responden dihitung dari jawaban berdasarkan pengisian kuesioner dari masingmasing pernyataan. Berikut pada gambar 16 merupakan grafik persentase jawaban rata-rata hasil pengujian dari 15 responden dari operator dan guru SMPN 4 Gunungsari:

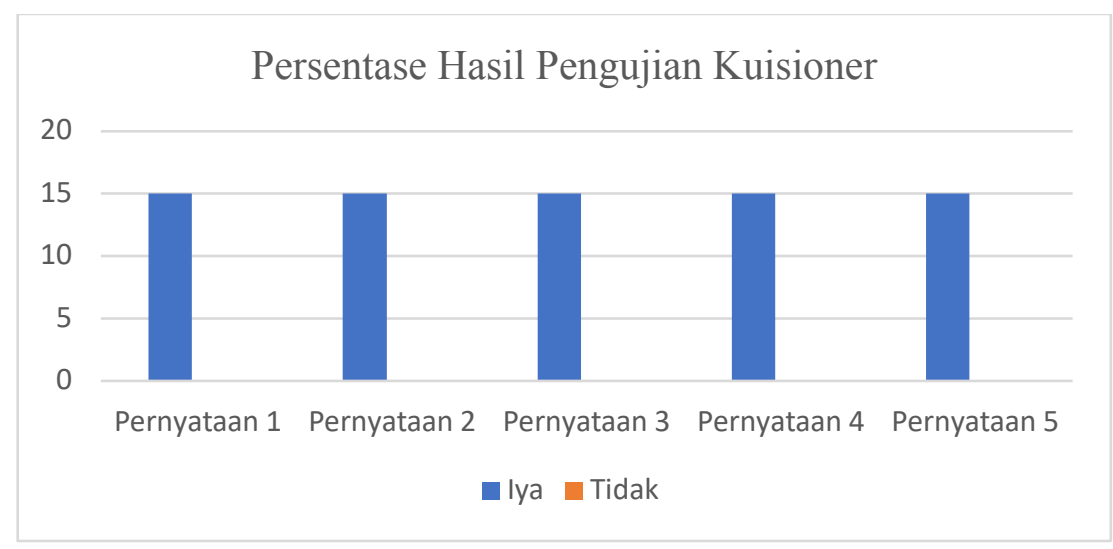

Gambar 15. Persentase hasil pengujian

Pada gambar 15 merupakan hasil dari persentase pengujian dari kuesioner yang diberikan mendapatkan nilai untuk pernyataan 1 nilai Iya diberikan oleh 15 orang responden, untuk pernyataan 2 nilai Iya diberikan oleh 15 orang responden, untuk pernyataan 3 nilai Iya diberikan oleh 15 orang responden, untuk pernyataan 4 nilai Iya diberikan oleh 15 orang responden dan untuk pernyataan 5 nilai Iya diberikan oleh 15 orang responden. Sehingga dapat disimpulkan bahwa dari responden setuju dengan sistem yang telah dibangun. 


\section{KESIMPULAN DAN SARAN}

\subsection{Kesimpulan}

Berdasarkan hasil Pengabdian Masyarakat di SMPN 4 Gunungsari berupa Sistem Informasi Company Profile berbasis website, maka didapatkan kesimpulan sebagai berikut :

1. Sistem informasi company profile pada SMPN 4 Gunungsari dapat digunakan untuk mengetahui informasi terbaru mengenai sekolah serta mempromosikan kepada masyarakat luas.

2. Fitur-fitur yang terdapat pada sistem informasi company profile ini, seperti informasi sekolah, tenaga pengajar, kontak yang dapat dihubungi serta informasi-informasi terkini seperti berita, agenda dan pengumuman terbaru sekolah.

3. Sistem informasi company profile SMPN 4 Gunungsari memiliki dua pungguna, yaitu user sebagai pengunjung dan administrator.

4. Kepuasan client terhadap sistem informasi yang telah dibuat dapat dilihat dari respon client terhadap

5.2. Saran pertanyaan yang ada di kuisioner yang telah diberikan, dari hasil responden didapatkan.

Adapun saran yang dapat diberikan penulis agar Sistem Informasi Company Profile berbasis website ini menjadi lebih baik di masa yang akan datang adalah sebagai berikut:

1. Melakukan perbaikan pada tampilan serta menambahkan fitur-fitur baru untuk dapat lebih menunjang kinerja dari sistem dan memudahkan operator dalam mengelola data-data informasi yang dimiliki SMPN 4 Gunungsari

2. Diharapkan kedepannya untuk selalu memperbaharui tampilan website agar terlihat lebih up to date mengikuti perkembangan teknologi IT.

\section{UCAPAN TERIMA KASIH}

Ucapan terima kasih kepada instansi SMPN 4 Gunungsari yang telah memberikan kesempatan melakukan kegiatan pengabdian masyarakat. Rekan-rekan staff dan guru-guru yang memberikan data dan informasi untuk dijadikan sebagai bahan dasar untuk pembuatan sistem. Serta kepada keluarga dan teman-teman yang membantu penulis dalam melaksanakan pengabdian ini.

\section{DAFTAR PUSTAKa}

[1] Roni Sulistya Nugraha, "Sistem Informasi Sekolah Di Surakarta Berbasis Website," Am. J. Orthod. Dentofac. Orthop., vol. 20, no. 1, pp. 1-8, 2016.

[2] Nurhasanah, "Penguasaan Hasil Belajar Menyulam Pada Pembuatan Cinderamata Oleh Peserta Didik Di Smpn 3 Lembang," 2015.

[3] Puspa Agita, "Perancangan Company Profile Berbasis Web Untuk Mempromosikan Tanjung Plaza Hotel Tretes.".

[4] American Journal of Sociology, " Adopsi Teknologi Informasi Terhadap Peningkatan Pelayanan Di Badan Pendapatan Daerah Provinsi Jawa Barat,” J. Chem. Inf. Model., vol. 53, no. 9, pp. 1689-1699, 2019.

[5] M. S. Janry Haposan U. P. Simanungkalit, S.Si., "Konsep Dasar Sistem Informasi ( Review )," Lect. Notes Sist. Inf., pp. 1-10, 2012.

[6] Siswanto, "Pengantar Sistem Informasi Geografik," Pengantar Sistem. Informasi., March, 2005, [Online]. Available: http://eprints.upnjatim.ac.id/2404/1/Buku_Pengantar_SIG.pdf.

[7] F. Magaline, B. N. Mahamudu, and E. Ho, "Sistem Informasi" Sist. Inf., p. 2019, 2019.

[8] A. Hanif, "Basis Data Basis Data," Arif Basofi, S.Kom. MT. Tek. Inform. PENS Makal., pp. 1-19, 2016.

[9] Anhar, "Panduan Menguasai PHP dan MySQL Secara Otodidak", Jakarta: Mediakita, 2010.

[10] Hartono, Hamzah, "Pengertian Website Dan Fungsinya", Ilmu Teknologi Informasi, pp. 2-7, 2014.

[11] Haviluddin, "Memahami Penggunaan UML (Unified Modelling Language)," Jurnal Informatika Mulawarman, vol. 6, No. 1, Februari 2011, pp. $1-15$.

[12] Dharwiyanti, Sri, P”engantar Unfied Modeling Language”, Jurnal Kuliah Umum IlmuKomputer.com, 2003.

[13] Peranginangin, "Teknik Cepat Menguasai PHP MySQL dalam Waktu yang Sangat Singkat”, Jakarta: Kuncikom, 2016.

[14] Alatas, Husein, "Responsive Web Design dengan PHP dan Bootstrap", Yogyakarta: Lokomedia, 2013.

[15] Hidayatullah, Priyanto, "Pemrograman Web", Bandung: Informatika Bandung, 2015.

[16] Chrisantus Tristanto, "Penggunaan Metode Waterfall untuk Pengembangan Sistem Monitoring dan Evaluasi Pembangunan Pedesaan,” Jurnal Teknologi Informasi ESIT, vol. XII, No. 1, April 2018, pp. 8 - 22. 